\title{
Effect of Hall Current on MHD Non-Newtonian Unsteady Casson Fluid Porous Rotating Disk Flow with a Uniform Electric Field
}

\author{
Kh. Abdul Maleque
}

\begin{abstract}
The effects of Hall current and a uniform electric field on non-Newtanian casson fluid porous rotating disk flow are examined. A uniform angular velocity, an axial uniform magnetic field and the Hall current are taken into considered. Examples of Casson fluid include jelly, tomato sauce, honey, soup and concentrated fruit juices, ect. Human blood can also be treated as Casson fluid. Considering the suitable similarity parameters the governing equations of the problem are then transformed into the non-linear ordinary differential equations. The ordinary similarity differential equations are then solved numerically by six order Runge-Kutta method and shooting method using the Nachtsheim- Swigert iteration technique.
\end{abstract}

Keywords - Non-Newtonian Casson fluid; MHD Flow, Hall effects; Electric field; Rotating disk;

\section{INTRODUCTION}

In $1827 \mathrm{M}$ Navier [1] has first developed the three dimensional equations of viscous flow and on the basis of an argument which involved the consideration of intermolecular forces by S. D. Poisson[2] in 1831,. Later B. de Saint Venant[3] in 1843 and G. G. Stokes[4] in 1845, the same equations were derived without the use of any such hypotheses. The fully three dimensional rotating disk flow was first developed by Von-Karman [5] in 1921. Cochran [6] pointed out Von-Karman's original momentum-integral solution to the problem contained errors. The fifth-order system as a singular perturbation problem was reformulated by Cochran. He corrected Van-Karman 's solution and then calculated more accurate values by numerical integration of the equations. Cochran's solutions were improved by Benton [7] and extended the hydrodynamic problem to the flow starting impulsively from rest. The boundary layer flow in the vicinity of a separation point on general three dimensional case discussed by Howarth[8] in 1951. The equations were reducible to pair of simultaneous ordinary third-order differential equations are showed by him..

\section{Kh. Abdul Maleque}

Professor of Mathematics

American International University-Bangladesh (AIUB).

Dhaka, Bangladesh

e-mail: maleque@aiub.edu; malequekh@gmail.com;
Hansan [9] discussed the possible forms of similarity requirements irrespective of the body shape and expressed the uniformed motion of the flow in tabular form. He presented a table showing the nature of the variations in the main stream components for which the governing equations to a set of ordinary differential equations. Later Zekerullah and Maleque [10] have showed that a restricted form of variation in temperature difference between the surface and the ambient fluid for three dimensional mixed convective flow. For convective boundary layer in orthogonal curvilinear surfaces the similarity requirements are made by Zekerullah and Maleque[11] and displayed in tabular form. Allen and Rilley[12] investigated out a three dimensional boundary layer calculation for the flow over a semi infinite circular cylinder. Al-Doss and Jerroch[13] dealt with the non Darcian mixed convection boundary layer flow about vertical cylinder. Kuiken [14] found the effect of uniform blowing through a rotating porous disk on the flow induced by this disk. Hassan and Hazem[15] and Maleque and Sattar[16-19] investigated the steady/unsteady convective flow due to a rotating disk with magnetic field and heat absorption effects also considering the variable properties. Maleque [20] studied the effects of combined temperature- and depth-dependent viscosity and hall current on an unsteady MHD laminar convective flow due to a rotating disk. Recently Maleque [21] investigated that Magnetohydrodynamic convective heat and mass transfer due to a rotating disk with thermal diffusion effect.

In many coating applications in the polymer processing industry especially in extraction of crude oil from petroleum products however fluids used to generate damage resistant surfacing are generally non-Newtonian. Many authors have published their papers on non-Newtonian fluids. Some of them are Acrivos et al [22], Mitschka [23], Rogovskii and Gorbis [24] and Sarma and Gupta [25]. A similarity solution for the power low fluid flow over a rotating disk studied by them. Rashaida et al [26] considered both flow and species from a rotating disk to a Bingham platic. In the category of non-Newtonian fluids, Casson fluid has distinct features. First in 1959 Cassion [27] presented the model for the flow of viscoelastic fluid. Human blood, jelly, tomato sauce , honey, soup and concentrated fruit juices, etc are the examples of Casson fluid. Several researcher published their excellent investigations on non Newtonian Casson fluid flow. Non- 
Newtonian mhd Casson fluid flow with heat transfer between two cylindrical disk/pipe studied by Eldabe et al [28] and Dash et. al [29]. The unsteady boundary layer Casson fluid flow on moving flat plate studied by Mostafa et al [30] while Nadeem et al [31] and Mukhopadhyay et al [32] studied the Casson MHD fluid over an exponentially shrinking sheet. Recently Nadeem et al [33] studied mhd Casson fluid flow past a porous linear stretching sheet. Very recently Maleque and Ghose[34] and Maleque [35] investigated the effects of a binary chemical reaction and activation energy on unsteady mhd non-Newtonian Casson fluid, heat and mass transfer flow due to ratating disk. In this present paper, the effects of hall current and a uniform electric field on non-Newtanian Casson fluid flow due to a porous rotating disk are examined. A uniform angular velocity, an axial uniform magnetic field and the Hall current are taken into considered. Considering the suitable similarity parameters the governing equations of the problem are then transformed into the non-linear ordinary differential equations and then solved. The ordinary similarity ordinary differential equations are then solved numerically by Nachtsheim- Swigert iteration technique and six order Runge-Kutta method. This problem is an extension work studied by Maleque [36].

\section{Governing EQUATIONS OF THE FLOW CONSIDERED:}

Considering the Mhd unsteady incompressible laminar boundary layer flow due to porous rotating disk. NonNewtonian Casson fluid and a uniform electric field have been considered. The induced magnetic field is neglected while the Hall effect is taken into consideration. The governing equations the fluid flow are \{Maleque [20]\}:

Mass equation:

$$
\vec{\nabla} \cdot \vec{q}=0
$$

Momentum equation:

$$
\frac{\partial \overrightarrow{\mathrm{q}}}{\partial \mathrm{t}}+(\overrightarrow{\mathrm{q}} . \nabla) \overrightarrow{\mathrm{q}}=-\frac{1}{\rho} \nabla \mathrm{p}+\left(1+\frac{1}{\lambda}\right) v \nabla^{2} \overrightarrow{\mathrm{q}}+\frac{1}{\rho}(\overrightarrow{\mathrm{J}} \times \overrightarrow{\mathrm{B}})
$$

The generalized Ohms' law:

$$
\vec{J}=\sigma[\vec{E}+\vec{q} \times \vec{B}-\beta(\vec{J} \times \vec{B})]
$$

The external uniform magnetic field $\overrightarrow{\mathrm{B}}=\left(0,0, B_{0}\right)$ and Electric field $\overrightarrow{\mathrm{E}}$ are normal to the surface of the disk. Very small unchanged magnetic Reynold's number $R_{e m}$ is considered. We assume that the insulated disk is rotating about z-axis with a angular velocity $\Omega$ in the $z=0$ plane with a uniform angular velocity. Here, $\rho$ is the density of the fluid, $v$ is the kinematic viscosity, $\sigma$ is the electric conductivity and $\mathrm{p}$ is the pressure.

The last term of equation (3) expressed as the Hall effect, where $\beta_{e}=\frac{1}{n e}$ is the Hall factor, $n$ is the electron concentration per unit volume and $-e$ is the charge of electron and $\lambda$ is the Casson parameter. On the basis of above mentioned physical configuration of the problem considered here is shown in the fig.1. Let and be the cylindrical polar coordinates and the velocity vector respectively. The continuity and momentum equations are take the form:

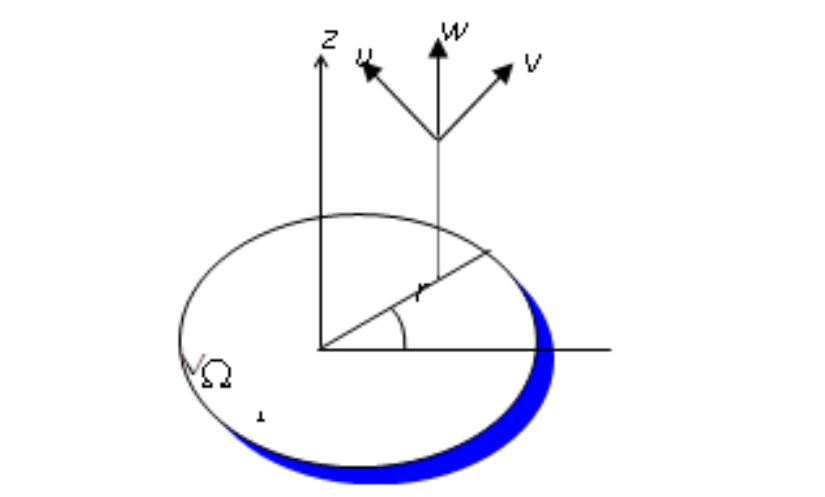

Fig. 1. The flow configuration and the coordinate system.

Let $(r, \phi, z)$ and $\vec{q}=(u, v, w)$ be the cylindrical polar coordinates and the velocity vector respectively. The continuity and momentum equations are take the form:

$$
\frac{\partial u}{\partial r}+\frac{u}{r}+\frac{\partial w}{\partial z}=0
$$

$$
\begin{gathered}
\frac{\partial u}{\partial t}+u \frac{\partial u}{\partial r}-\frac{v^{2}}{r}+w \frac{\partial u}{\partial z} \\
+\frac{\sigma B_{0}^{2}}{\rho\left(1+m^{2}\right)}\left(u-m v-\frac{E_{0}}{B_{0}}\right)+\frac{1}{\rho} \frac{\partial p}{\partial r} \\
=v\left(1+\frac{1}{\lambda}\right)\left(\frac{\partial^{2} u}{\partial r^{2}}+\frac{1}{r} \frac{\partial u}{\partial r}-\frac{u}{r^{2}}+\frac{\partial^{2} u}{\partial z^{2}}\right) \\
\frac{\partial v}{\partial t}+u \frac{\partial v}{\partial r}+\frac{u v}{r}+w \frac{\partial v}{\partial z}+\frac{\sigma B_{0}^{2}}{\rho\left(1+m^{2}\right)}\left(v+m u+\frac{E_{0}}{B_{0}}\right) \\
=v\left(1+\frac{1}{\lambda}\right)\left(\frac{\partial^{2} v}{\partial r^{2}}+\frac{1}{r} \frac{\partial v}{\partial r}-\frac{v}{r^{2}}+\frac{\partial^{2} v}{\partial z^{2}}\right) \ldots(6) \\
\frac{\partial w}{\partial t}+u \frac{\partial w}{\partial r}+w \frac{\partial w}{\partial z}+\frac{1}{\rho} \frac{\partial p}{\partial z} \\
=v\left(1+\frac{1}{\lambda}\right)\left(\frac{\partial^{2} w}{\partial r^{2}}+\frac{1}{r} \frac{\partial w}{\partial r}+\frac{\partial^{2} w}{\partial z^{2}}\right) \ldots(7)
\end{gathered}
$$

here $m=\left(\sigma \beta_{e} B_{0}\right)$ denotes the Hall parameter.

The initial and boundary conditions are

$$
\left.\begin{array}{l}
u=0, \quad v=\Omega r, \quad w=w_{w} \text { at } z=0 \\
u=0, v=0, \quad p=p_{\infty} \quad \text { as } z \rightarrow \infty
\end{array}\right\} .
$$

The conditions at $z=0$ represent no-slip conditions, while those at $z \rightarrow \infty$ represent the far field conditions. 


\section{SIMILARITY SOLUTIONS}

To reduce the governing equations (4) - (7) to ordinary differential equations introducing the following dimensionless quantities $\{$ see Maleque and Sattar[37]\}:

$$
\left.\begin{array}{l}
\eta=\frac{z}{\delta(t)}, u=r \Omega F(\eta), v=r \Omega G(\eta), \\
w=\frac{v}{\delta(t)} H(\eta) \text { and } p=v \rho \Omega P(\eta),
\end{array}\right\}
$$

where scale factor $\delta=\delta(t)$ which is a function of time $t$.

In equations (4) - (7), introducing non-dimensional similarity variables from equation (9), we have the following set of nonlinear ordinary differential equations

$$
H^{\prime}+2 R_{e} F=0
$$

$$
\begin{gathered}
\left(1+\frac{1}{\lambda}\right) F^{\prime \prime}+\frac{\delta}{v} \frac{d \delta}{d t} \eta F^{\prime}-H F^{\prime}-R_{e}\left(F^{2}-G^{2}\right) \\
-\frac{R_{e} M}{1+m^{2}}(F-m G+K)=0 \\
\left(1+\frac{1}{\lambda}\right) G^{\prime \prime}+\frac{\delta}{v} \frac{d \delta}{d t} \eta G^{\prime}-2 R_{e} F G-H G^{\prime} \\
-\frac{R_{e} M}{1+m^{2}}(G+m F-K)=0
\end{gathered}
$$

$$
\left(1+\frac{1}{\lambda}\right) H^{\prime \prime}+\frac{\delta}{v} \frac{d \delta}{d t}\left(H+\eta H^{\prime}\right)-H H^{\prime}+R_{e} P^{\prime}=0
$$

where $M=\sigma B_{0}^{2} / \Omega \rho, R_{e}=\Omega \delta^{2} / \nu$ and $K=-E_{0} / \Omega r B_{0}$, are the magnetic parameter, Reynolds number and the loading coefficient respectively. For the acceleration regime (of the pump) $K>1$ and the regime of breaking of flow $K<1$. The interval $0<K<1$ comprises the regime of the MHD generator ( $\{$ see Blums [38] $\}$ ).

The equations (10) - (13) appear the term $\frac{\delta}{v} \frac{d \delta}{d t}$. For the similarity solution $\frac{\delta}{v} \frac{d \delta}{d t}$ must be a constant quantity Maleque [26].

In equations (10) to (12) by assuming that

$$
\frac{\delta \delta^{\prime}}{v}=A(\text { Constant })
$$

From equation (13), it has been found

$$
\delta(t)=\sqrt{2 A v t}+L
$$

where $L$ is the integrating constant. If $t=0$ or $A=0$ then $\delta=L$ represents the length scale for steady flow and for unsteady flow $A \neq 0$ that is, $\delta$ represents the length scale for unsteady flow $A=2$ is considered by Maleque $[39,40]$ for a class solution. The nature of the solution would not be changed for the different value of $A$. Finally, using equation (14) in equations (11) - (13) respectively, we have

$$
H^{\prime}+2 R_{e} F=0
$$

$$
\begin{gathered}
\left(1+\frac{1}{\lambda}\right) F^{\prime \prime}+\eta A F^{\prime}-H F^{\prime}-R_{e}\left(F^{2}-G^{2}\right) \\
-\frac{R_{e} M}{1+m^{2}}(F-m G+K)=0 \\
\left(1+\frac{1}{\lambda}\right) G^{\prime \prime}+\eta A G^{\prime}-2 R_{e} F G-H G^{\prime} \\
-\frac{R_{e} M}{1+m^{2}}(G+m F-K)=0 \\
\left(1+\frac{1}{\lambda}\right) H^{\prime \prime}+2 H+\eta A H^{\prime} \\
-H H^{\prime}+R_{e} P^{\prime}=0
\end{gathered}
$$

The initial and boundary conditions (8) becomes

$$
\left.\begin{array}{l}
F=0, \quad H=W_{s}, \quad G=1 \quad \text { at } \eta=0, \\
F=G=0, \quad P=0 \quad \text { as } \eta \rightarrow \infty .
\end{array}\right\} \ldots
$$

Where $W_{s}=\delta w_{w} / v$. For a uniform suction $\left(W_{s}<0\right)$ or injection $\left(W_{s}>0\right)$ at the plane of the disk s see Maleque and Sattar [21-22]\}. Prime $\left({ }^{\prime}\right)$ represents the differentiation with respect to $\eta$.

\section{Solution:}

We obtained the numerical solutions of reduced ODEs (16)-(18) by six order Runge-Kutta method with the help of Nachtsheim and Swigert [41]. Runge - Kutta method is the solver of initial value problems. To convert boundary value problem to initial value problem the Nachtsheim - Swigert iteration technique the outer boundary conditions may be functionally represented by the first order Taylor's series as

$$
\begin{aligned}
& F\left(\eta_{\max }\right)=F(X, Y)=F_{0}\left(\eta_{\max }\right)+\Delta X F_{X}+\Delta Y F_{Y}=\delta_{1} \\
& G\left(\eta_{\max }\right)=G(X, Y)=G_{0}\left(\eta_{\max }\right)+\Delta X G_{X}+\Delta Y G_{Y}=\delta_{2}
\end{aligned}
$$

the asymptotic convergence are considered by

$$
F^{\prime}\left(\eta_{\max }\right)=F^{\prime}(X, Y)=F^{\prime}\left(\eta_{\max }\right)+\Delta X F_{X}^{\prime}+\Delta Y F_{Y}^{\prime}=\delta_{3},
$$




$$
G^{\prime}\left(\eta_{\max }\right)=G^{\prime}(X, Y)=G_{0}^{\prime}\left(\eta_{\max }\right)+\Delta X G_{X}^{\prime}+\Delta Y G_{Y}^{\prime}=\delta_{4},
$$

where, $X=F^{\prime}(0), Y=G^{\prime}(0)$, and $X, Y$ subscripts indicate partial differentiation, e.g., $\quad F_{X}=\partial F / \partial F^{\prime}(0)$. The subscript 0 indicates the value of the function at $\eta_{\max }$ to be determined from the trial integration.

By least square method finding the minimum values of the error $E=\delta_{1}^{2}+\delta_{2}^{2}+\delta_{3}^{2}+\delta_{4}^{2}$ with respect to $X$, and $Y$. We need to differentiate $E$ with respect to $X$, and $Y$ to obtain $\Delta X$, and $\Delta Y$ respectively. A computer program was developed for the numerical solutions of the basic non-linear differential equations of our problem by adopting Nachtsheim and Swigert iteration technique, where the iteration technique was adopted as a six ordered Range-Kutta method of integration. In this different phases various groups of the parameters $\gamma, W_{s}, M$ and $m$ were considered.. For a convergence criterion of $10^{-5}$ for all the computations the step size $\Delta \eta=0.01$ was selected in almost all of different phases mentioned above. Stating $\eta_{\infty}=\eta_{\infty}+\Delta \eta$, the value of $\eta_{\infty}$ was found to each iteration loop. $\left(\eta_{\infty}\right)_{\max }$, to each group of the parameters, has been obtained when value of unknown boundary conditions at $\eta=0$ not change to successful loop with error less than $10^{-5}$. However, different step sizes such as $\Delta \eta=0.01$, $\Delta \eta=0.005$ and $\Delta \eta=0.001$ were also tried and the obtained solutions have been found to be independent of the step sizes as observed in Fig.18.

The computer program was developed with FORTRAN language and then we solved the equations (16)-(18) numerically by Nachtsheim-Swigert [41] iteration technique with the sixth order Range-Kutta integration scheme and numerical results were shown graphically and tabular forms.

The results of the numerical calculations are presented in the form of the radial velocity, tangential velocity and axial velocity profiles, which depict the effects of various parameters $\lambda, K, W_{s}, m$ and $M$ entering into the fluid flow due to the rotating disk. It is therefore, pertinent to enquire the effects of the variation of each of the parameter when the others are kept constant.

The Newtonian formulae can be applied for finding the tangential shear stress $\tau_{t}$ and the radial shear stress $\tau_{r}$,

$$
\begin{gathered}
\tau_{t}=\mu\left(1+\frac{1}{\lambda}\right)\left(\frac{\partial v}{\partial z}+\frac{1}{r} \frac{\partial w}{\partial \phi}\right)_{z=0} \\
=\mu r \Omega\left(1+\frac{1}{\lambda}\right)\left(\frac{\Omega}{R_{e} v}\right)^{\frac{1}{2}} g^{\prime}(0) \\
\text { and, } \tau_{r}=\mu\left(1+\frac{1}{\lambda}\right)\left(\frac{\partial u}{\partial z}+\frac{\partial w}{\partial r}\right)_{z}=0 \\
=\mu r \Omega\left(1+\frac{1}{\lambda}\right)\left(\frac{\Omega}{R_{e} v}\right)^{\frac{1}{2}} F^{\prime}(0) .
\end{gathered}
$$

The numerical computational results of the velocities profiles and the corresponding shearing stresses are organized graphically and in tabular form respectively.

\section{RESUltS AND Discussion:}

The results were carried out for various values of casson parameter $\lambda$, suction/injection parameter $W_{s}$, Reynolds number $R$, Magnetic interaction parameter $M$ and loading parameter $K$ and are presented in the form of the radial velocity, tangential velocity and axial velocity profiles. It is therefore, pertinent to enquire the effects of the variation of each of the parameter when the others are kept constant.

For strong non-Newtonian fluid $\lambda \rightarrow 0$ is considered but $\lambda \rightarrow \infty$ means Casson term may be neglected and $K=0$ represents uniform electric field is not to be considered.

For constant property case our results have been compared with those of Coachran [6] and Benton [7] in table-2 in order to highlight the validity of the numerical computations adopted in the present investigation. The comparisons show excellent agreements, hence an encouragement for the use of the present numerical computations.

\section{A. Casson parameter ( $\lambda$ ) effect:}

The flows becomes strongly non-Newtonian Casson fluid flow for Casson parameter $\lambda \rightarrow 0(=0.1)$ but Casson term is neglected for $\lambda \rightarrow \infty(=1000)$ that means the flow becomes Newtonian fluid flow. Fig. 2 - Fig.4 shows the effect of Casson parameter $\lambda$ on the radial, tangential and axial velocity profiles respectively. Fig. 2 shows that the decreasing values of Casson parameter lead to decrease the velocity profiles. Also, it has been found that for Newtonian fluid flow $\lambda \rightarrow \infty(=1000)$ the boundary layer is closed to the disk and the boundary layer separations are found for nonNewtonian fluid. It has been found the difference between the radial velocity profiles for $\lambda \rightarrow \infty(=1000)$ and $\lambda=1.0$ that the velocity profile decreases in the boundary layer $0<\eta<0.8$ but decrease for $\eta>0.8$ with the decreasing values of casson parameter $\lambda$ and so on for $\lambda=0.2$ and $\lambda=0.1$.

For decreasing values of $\lambda$ lead to increase the boundary layer thickness is decreasing for decreasing values of Casson parameter $\lambda$. That is the radian frictional force decreases for strong casson fluid flow also agreed with table -2 . The effects of Casson fluid parameter $\lambda$ on tangential velocity profiles are shown in Fig.3. The tangential velocity increases for increasing values of Casson parameter $\lambda$. The velocity profile shows its usual trend of gradual decay for casson fluid flow. It has been also found from Fig. 3 that for strong casson fluid the tangential boundary layer thickness is closed to the wall means high tangential frictional forces are appeared also shown in table-1(c). It is investigated from Fig.4 that increasing values of $\lambda$ lead to increase the axial velocity.

\section{B. Magnetic interaction parameter $M$ :}

The effect of the magnetic parameter $\boldsymbol{M}$ on the radial, the tangential and the axial velocity profiles shown in Fig.5 - 
Fig.7. The parameter $\boldsymbol{M}$ has marked effect on the radial velocity and tangential velocity profiles. The parameter $\boldsymbol{M}$ does not enter directly into the axial velocity, but it influences come through the solution of the radial and the tangential velocities.

It has been found from the figures Fig.5 - Fig.7 that the increasing values of $\boldsymbol{M}$ lead to decrease $\boldsymbol{F}, \boldsymbol{G}$ and $\boldsymbol{H}$ velocity profiles. Increasing the magnetic interaction parameter has the effect of damping the fluid velocity profiles. This is because the application of a transverse magnetic field normal to the flow direction will result in a resistive force (Lorentz force) similar to the drag force which tends to resist the fluid flow and thus reducing its velocity. Both tangential and radial shearing stresses decrease for increasing values of magnetic interaction parameter $\boldsymbol{M}$ shown in table-1(b).

\section{Loading parameter $K$ :}

Fig.8-Fig.10 show that the effects of the radial, the tangential and the axial velocity profiles for different values of loading coefficient $\boldsymbol{K}$ respectively. $\boldsymbol{K}<1$ corresponds to the regime of breaking of flow but $K>1$ corresponds to the acceleration regime (of the pump). The interval $0<\boldsymbol{K}<1$ comprises the regime of the MHD generator (see Blums [38]). In our present investigation we have considered the interval -1 $<\boldsymbol{K}<1$. From Fig.7, it has been found that the increasing values loading coefficient $\boldsymbol{K}$ lead to decrease the radial velocity profile. For constant angular velocity and $\boldsymbol{K}=-1$, it is found from $\boldsymbol{E}_{\mathbf{0}}=\boldsymbol{\Omega} \boldsymbol{r} \boldsymbol{B}_{\boldsymbol{0}}$ that the electric field is proportional to the magnetic field. Similar effects of magnetic field and electric field are to be found on radial velocity profiles, the tangential and axial velocity profiles. The increasing values of $\boldsymbol{K}$ lead to the increasing values of the tangential and axial velocity profiles shown in fig. 8 and Fig.9 respectively.

\section{Hall Current parameter $m$ :}

Fig.11-Fig.13 show the effects of Hall current parameter on the radial, the tangential and the axial velocities for the fixed values of the parameters $\lambda, W_{s}, \boldsymbol{K}$ and $\boldsymbol{M}$. It has been found from these figures Hall current parameter $\boldsymbol{m}$ has a sensible effect on the velocity profiles. The radial and the axial velocities increase for the limiting increasing values of $\boldsymbol{m}$ within 0 to 2.0 (not precisely determined), but But if the magnitude of $\boldsymbol{m}$ is increased beyond the limit of 2.0(possibly), the velocity profiles show a decreasing effect shown in Fig. 11 and Fig.13. This phenomenon has been explained by Hassan and Attia [19]. This is due to the fact that for large values of $\boldsymbol{m}$, the term $1 /\left(1+\boldsymbol{m}^{2}\right)$ is very small and hence the resistive effect of the magnetic field is diminished. It has been observed from Fig. 12 that the tangential velocity increases with the increasing values of Hall parameter $\boldsymbol{m}$.

\section{E. Suction/injection parameter $W_{S}$ :}

Fig.14 to Fig.16 showed the radial, the tangential and the axial velocity profiles for different values of suction and injection parameter $\boldsymbol{W}_{\boldsymbol{S}}$ kept the fixed values of other parameter say $\boldsymbol{K}=0.05, \boldsymbol{M}=0.05$ and $\lambda=0.5$. The axial velocity is nearly constant for suction $W_{S}=-1$. The tangential velocity decays rapidly away closed to the surface while very little radial velocity is found. It has been observed from these figure that suction stabilizes the boundary layer is also apparent. The boundary layer is increasingly blown away from the disk to form an interlayer between the injection and the outer flow regions for the injection $\left(\boldsymbol{W}_{S}>0\right)$ shown in Fig.14 to Fig.16. Higher injection velocities have the tendency to destabilize the laminar flow found from Fig.14-Fig16.

In Fig. 14, it is observed that for high values of injection parameter $\left(\boldsymbol{W}_{S}=4\right)$, the radial velocity overshoot and is closed to boundary of the surface. Opposite effect has been found for negative values of the parameter $\boldsymbol{W}_{S}$. This is due to the fact that, with increasing values of $\boldsymbol{W}_{S}$, the injected flow can sustain axial motion to greater distances from the wall. Then, near the wall, the radial flow which is fed by the axial flow is expected to decrease as the injected parameter increases. Opposite effects are found for strong suction $\boldsymbol{W}_{S}<-1$. Fig. 15 shows the effect of $\boldsymbol{W}_{\boldsymbol{S}}$ on tangential velocity. It is observed that the parameter $\boldsymbol{W}_{\boldsymbol{s}}$ leads the increasing values of tangential parameter. Fig. 16 shows the effect of the axial velocity for the different values of $\boldsymbol{W}_{\boldsymbol{S}}$. It is observed from the figure that the axial velocity has constant effect for $\boldsymbol{W}_{S}=-1$.

\section{F. Unsteady parameter A:}

In equation (15), $\boldsymbol{A}=0$ then $\boldsymbol{\delta}=\boldsymbol{L}$ represents the length scale for steady flow and for unsteady flow $\boldsymbol{A} \neq 0$ that is, $\boldsymbol{\delta}$ represents the length scale for unsteady flow. The comparison has been made for steady and unsteady flow on radial, tangential and axial velocities shown in Fig.17.

Finally the boundary layer thickness is close to the wall for unsteady flow. The effects of various parameters ( $\boldsymbol{R} \boldsymbol{e}$, and $\boldsymbol{M})$ on the tangential and radial shearing stresses $\tau_{t}$ and $\tau_{r}$ are shown in Table-1. From Table-1, it is observed that the tangential shearing stress decreases and the radial shearing stress increases owing to the increase of rotating parameter $\boldsymbol{R}$ and magnetic interaction parameter $\boldsymbol{M}$.

\section{Conclusions:}

In the present paper we have investigated the effects of Hall current parameter, Casson parameter, magnetic parameter, electric loading parameter and suction/injection parameter on an unsteady MHD non Newtonian convective flow induced by an infinite rotating porous disk. We reduced the partial differential equations to ordinary differential equations by introducing suitable similarity variables and then solved numerically by Nachtsheim and Swigert [36] iteration technique based on sixth-order Range-Kutta and shooting method.

We have made the following conclusions as a result of the computations:

1. The decreasing values of Casson parameter $\lambda$ lead to the decreasing values of the radial, tangential and axial velocity profiles.

2. Increasing the magnetic interaction parameter $\boldsymbol{M}$ has the effect of damping the fluid velocity profiles. This is because the application of a transverse magnetic field normal to the flow direction will result in a resistive force (Lorentz force) similar to the drag force which tends to resist the fluid flow and thus reducing its velocity.

3. The increasing values loading coefficient $\boldsymbol{K}$ lead to decrease the radial velocity profile but the increasing values of $\boldsymbol{K}$ lead to the increasing values of the tangential and axial velocity profiles.

4. Hall current parameter $\boldsymbol{m}$ has a sensible effect on the velocity profiles. The radial and the axial velocities increase for the limiting increasing values of $\boldsymbol{m}$ within 0 to 2.0. The resistive effects of the magnetic field is diminished and hence the radial and axial velocity profiles decreases with the increase of $\boldsymbol{m}$. 
5. The axial velocity is nearly constant for suction $\boldsymbol{W}_{S}=-1$. The tangential velocity decays rapidly away closed to the surface while very little radial velocity is found. It has been observed from these figure that suction stabilizes the boundary layer is also apparent. The boundary layer is increasingly blown away from the disk to form an interlayer between the injection and the outer flow regions for the injection $\left(\boldsymbol{W}_{\boldsymbol{S}}>0\right)$.

TABLE I. THE RADIAL AND THE TANGENTIAL SKIN FRICTION COEFFICIENTS FOR THE DIFFERENT VALUES OF $R E, M$ AND $\lambda$ FOR $M=0.1, K$ $=0.5$.

\begin{tabular}{|c|c|c|}
\hline$R_{e}$ & $F^{\prime}(0)$ & $G^{\prime}(0)$ \\
\hline 0.0 & 0.00000 & -1.15363 \\
2.0 & 0.57187 & -1.45922 \\
4.0 & 0.94130 & -1.82698 \\
6.0 & 1.21441 & -2.14930 \\
8.0 & 1.43853 & -2.43329 \\
10.0 & 1.63254 & -2.68902 \\
\hline
\end{tabular}

(b) For $R e=1.0, \mathrm{~m}=0.1$ and $\lambda=0.1$

\begin{tabular}{|c|c|c|}
\hline$M$ & $F^{\prime}(0)$ & $G^{\prime}(0)$ \\
\hline 0.0 & 0.24233 & -1.16238 \\
0.5 & 0.23635 & -1.33993 \\
1.0 & 0.23242 & -1.50118 \\
2.0 & 0.22842 & -1.78734 \\
3.0 & 0.22799 & -2.03839 \\
4.0 & 0.22766 & -2.26385 \\
\hline
\end{tabular}

(c) For $\mathrm{M}=0.5, \mathrm{~m}=0.1$ and $\mathrm{Re}=1$

\begin{tabular}{|c|c|c|}
\hline$\lambda$ & $F^{\prime}(0)$ & $G^{\prime}(0)$ \\
\hline 0.0001 & 0.0011069 & -0.0295230 \\
\hline 0.001 & 0.0052883 & -0.0508785 \\
\hline 0.010 & 0.0237140 & -0.1189105 \\
\hline 0.100 & 0.0797787 & -0.3365182 \\
\hline 0.500 & 0.1558607 & -0.5981541 \\
\hline 1.000 & 0.1932840 & -0.7070581 \\
\hline 10.0 & 0.2805427 & -0.9211743 \\
\hline$\infty$ & 0.2805427 & -0.9211743 \\
\hline
\end{tabular}

$$
W_{s}=0.5, m=0.1
$$$$
R=1.0, M=0.1, \text { and } K=0.5
$$

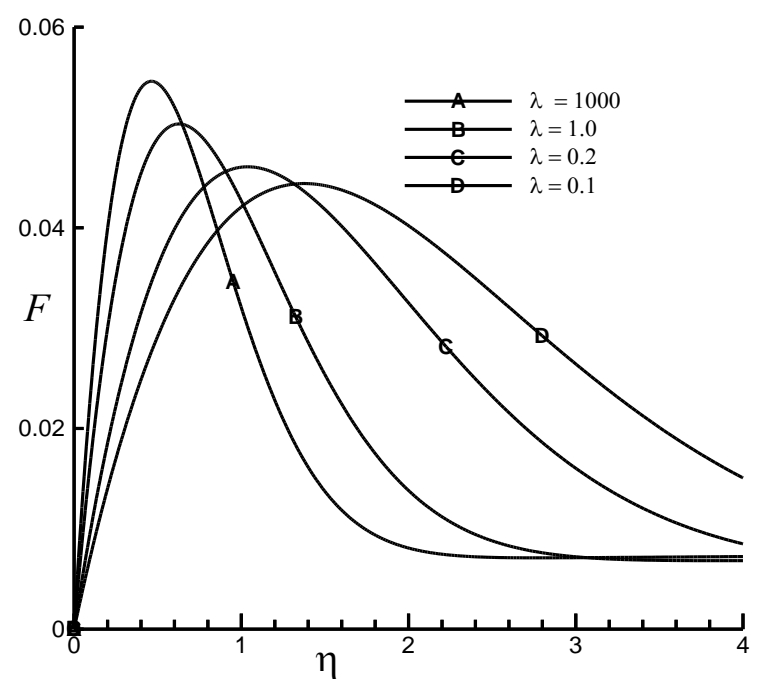

Fig. 2. Effects of $\lambda$ on the radial velocity profiles.

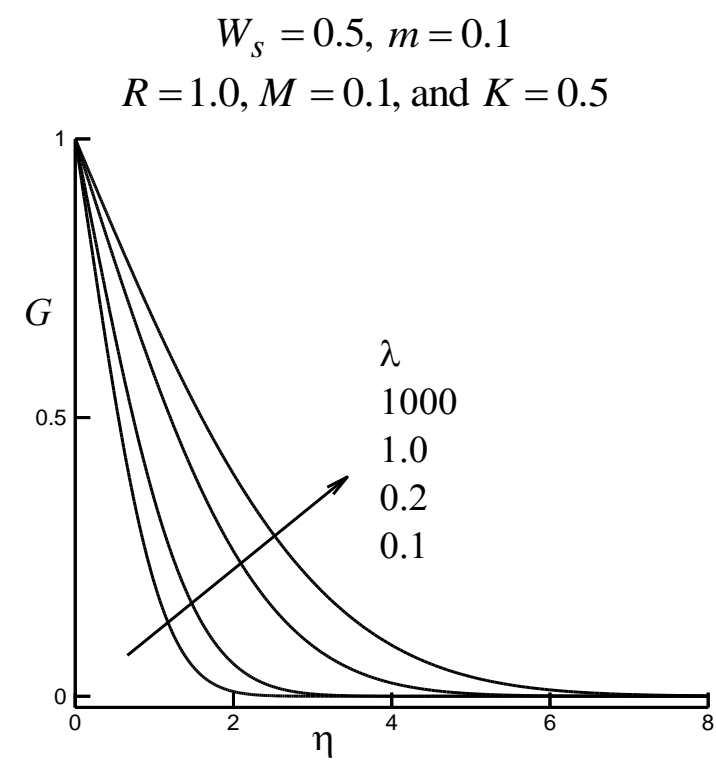

Fig. 3. Effects of $\lambda$ on the tangential velocity profiles.

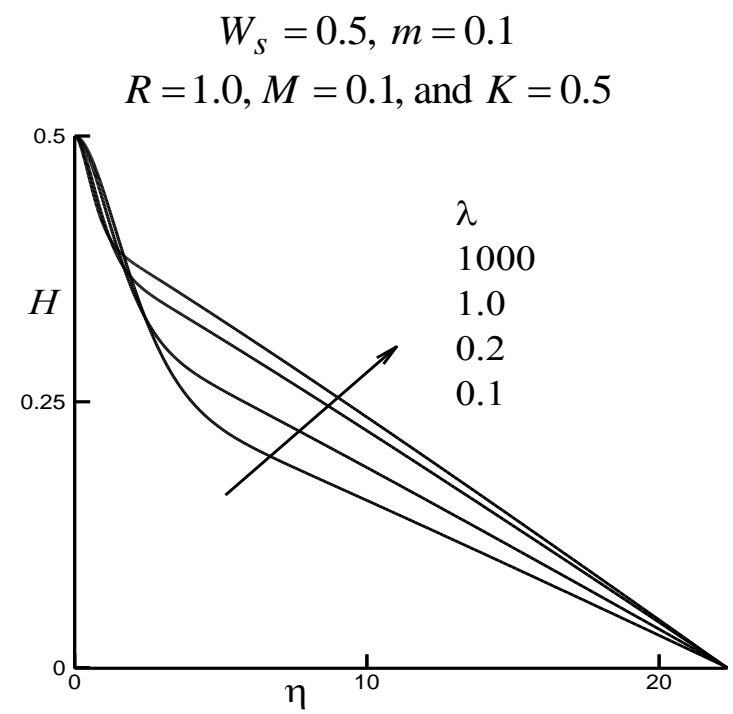

Fig. 4. Effects of $\lambda$ on the axial velocity profiles.

$$
\begin{gathered}
W_{s}=0.5, m=0.1 \\
R=1.0, \lambda=0.5, \text { and } K=0.5
\end{gathered}
$$

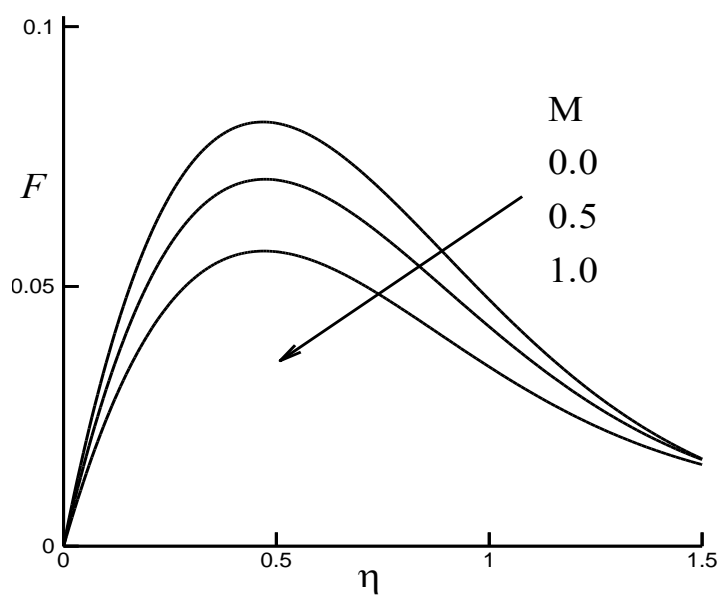

Fig. 5. Effects of $M$ on the radial velocity profiles. 


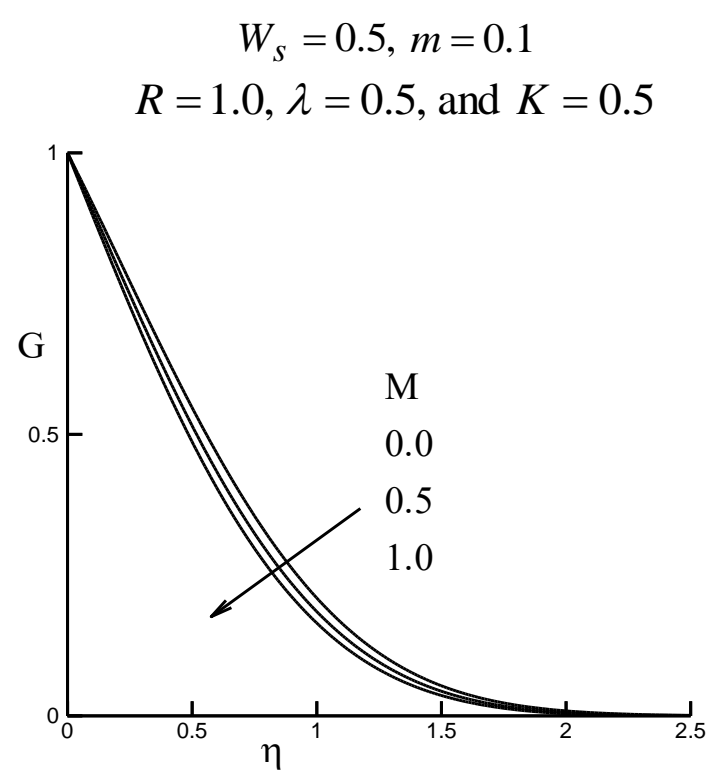

Fig. 6. Effects of $M$ on the tangential velocity profiles. $M$

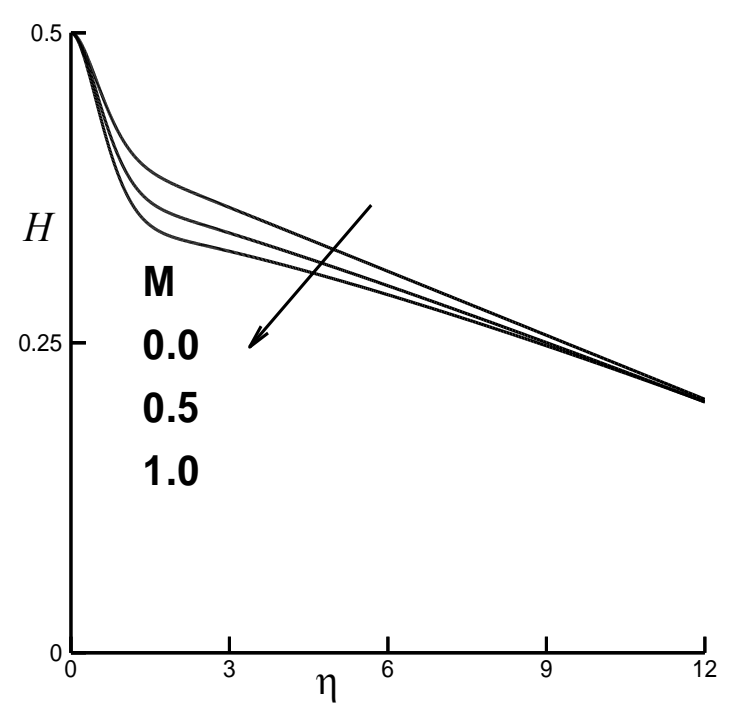

Fig. 7. Effects of $M$ on the axial velocity profiles.

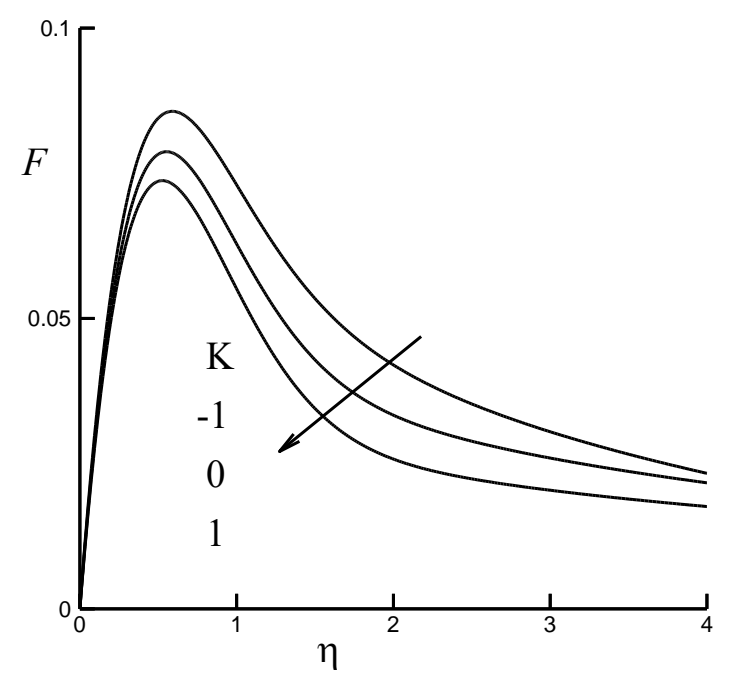

Fig. 8. Effects of $K$ on the radial velocity profiles.

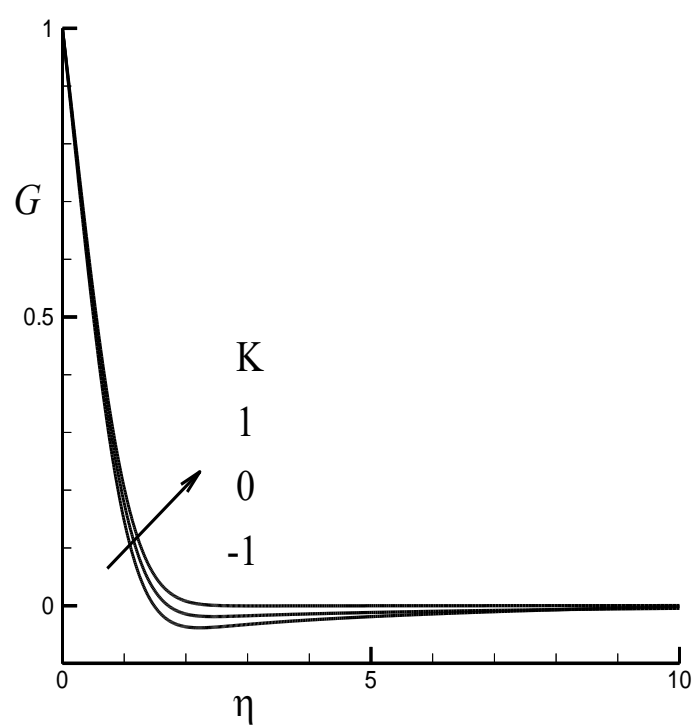

Fig. 9. Effects of $K$ on the tangential velocity profiles.

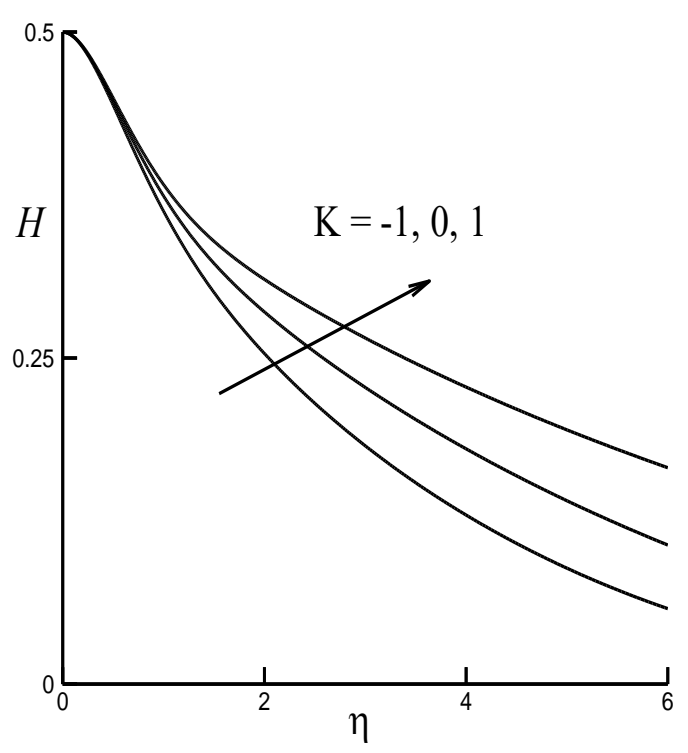

Fig. 10. Effects of $K$ on the axial velocity profiles.

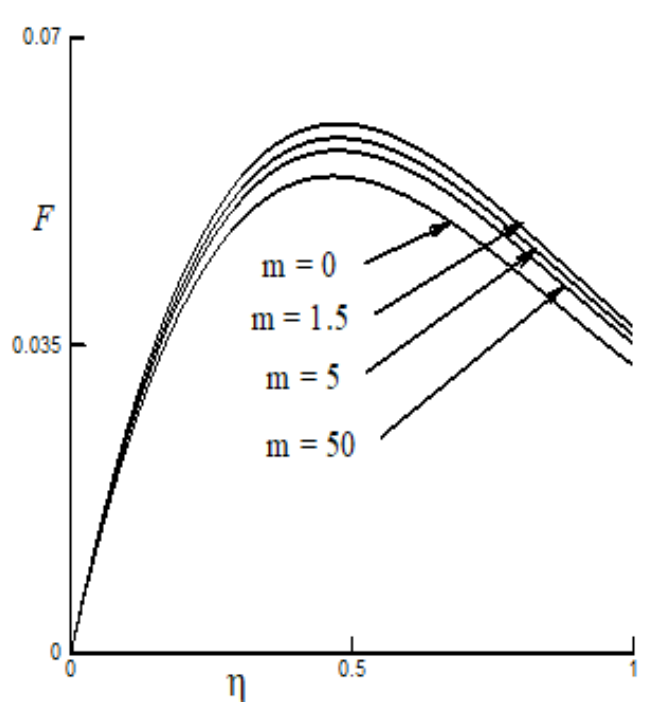

Fig. 11. Effects of $m$ on the radian velocity profiles. 


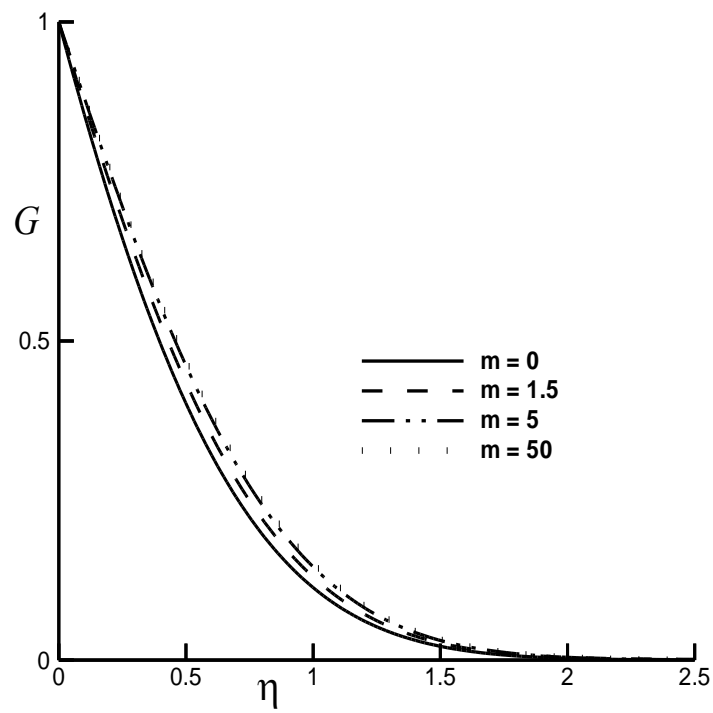

Fig. 12. Effects of $\boldsymbol{m}$ on the tangential velocity profiles.

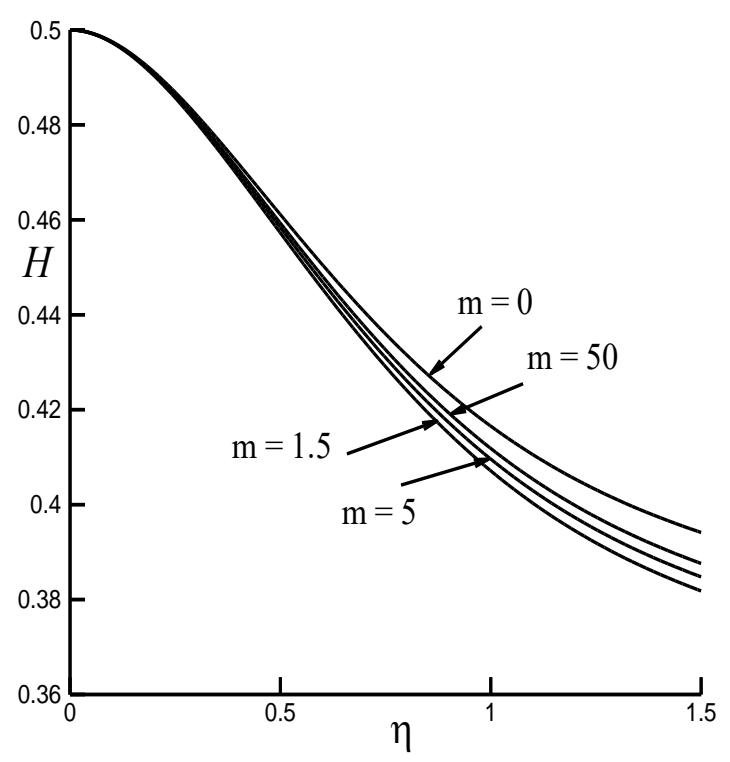

Fig. 13. Effects of $m$ on the axial velocity profiles.

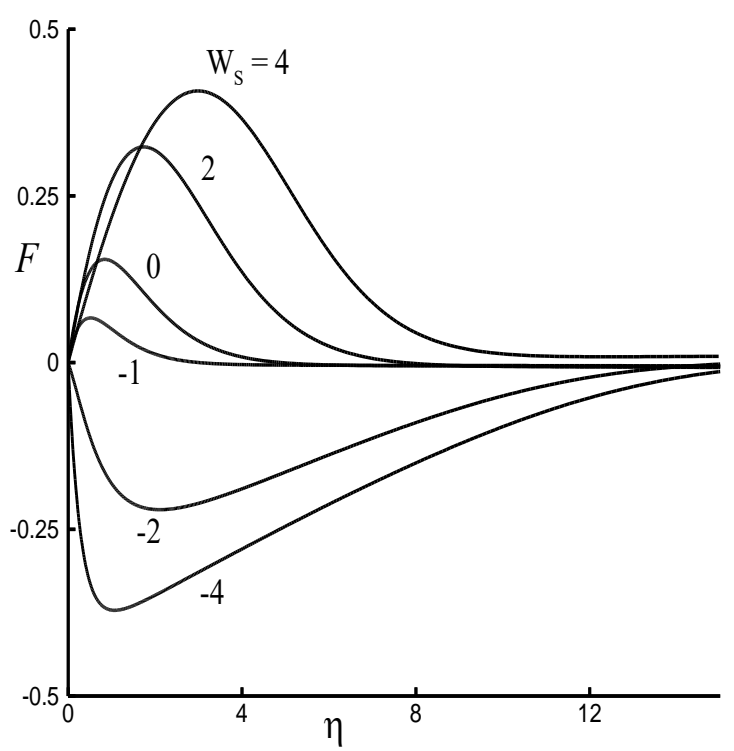

Fig. 14. Effect of $W_{S}$ on the radial velocity profiles.

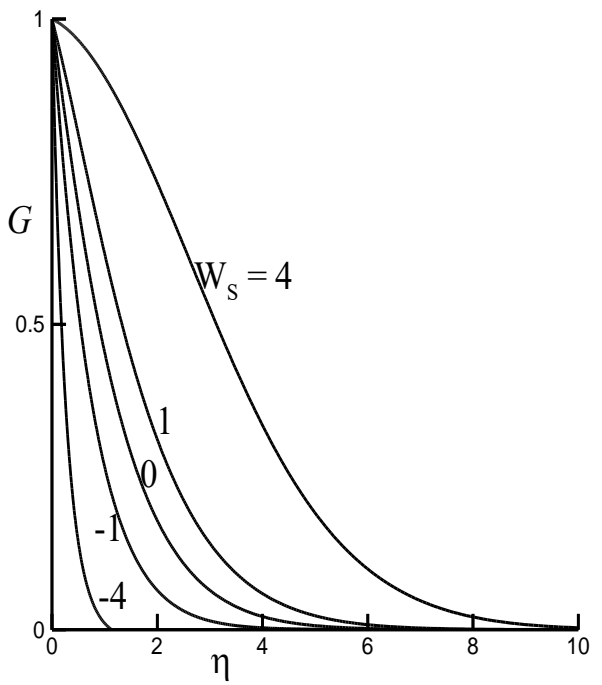

Fig. 15. Effect of $W_{S}$ on the tangential velocity profiles.

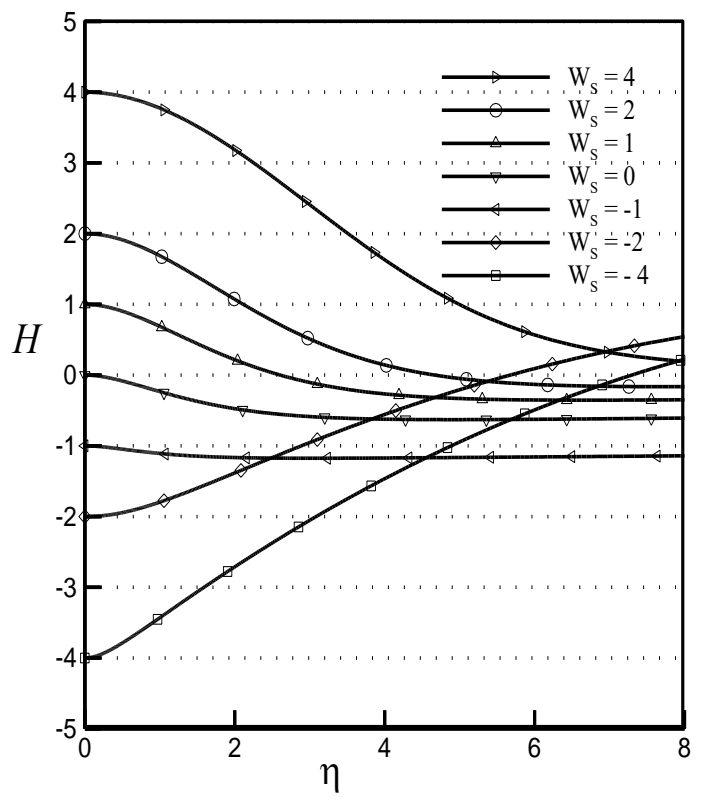

Fig. 16. Effect of $W_{S}$ on the axial velocity profiles.

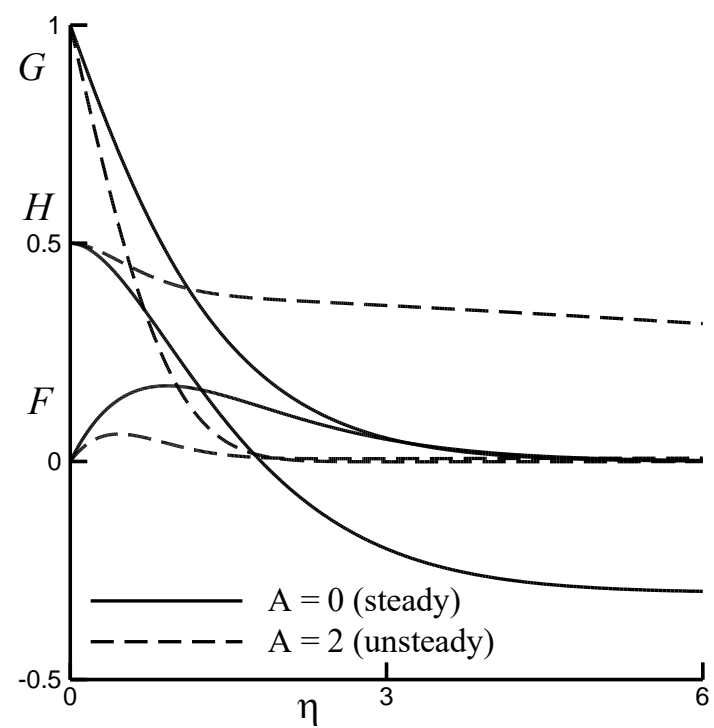

Fig. 17. The radial, the tangential and the axial velocity profiles for steady and unsteady cases. 


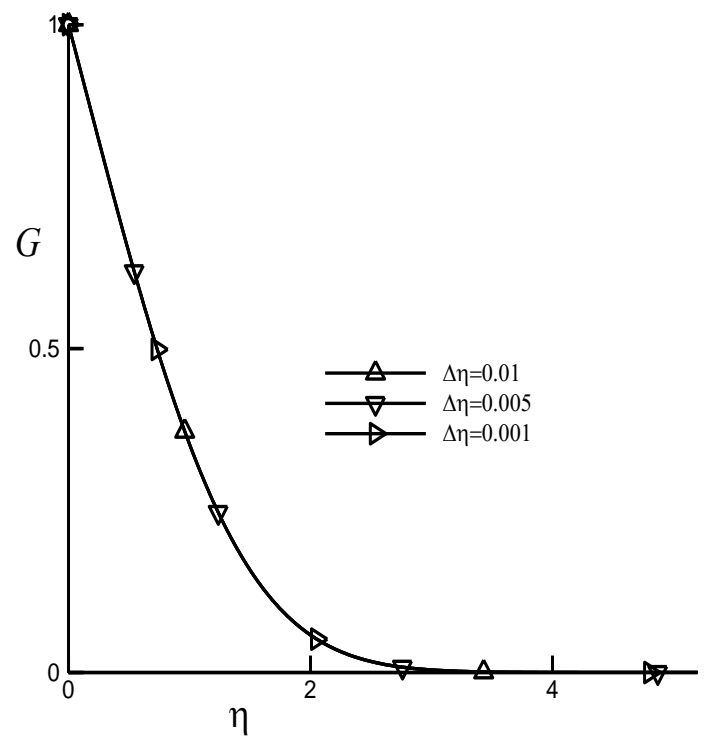

Fig. 18. The tangential velocity profiles for different step sizes.

\section{REFERENCES}

[1] M. Navier, "Memoire sur les Lois du Mouvement des Fluides,Mem." De I'Acad. D. Sci.6, 1827, 389-416.

[2] S. D.. Poisson, " Memoire sur les equations generales de I'equilibre et du movement descorps solides elastiques et des Fluids”, Jour. de I'Ecole polytechn. 13, 1831, 139-186.

[3] B. DE. ST. VENANT, "Note a joindre un memoire sur la dynamique des fluids." Comptes. Rendus, 17, 1843,1240-1244.

[4] G. G. Stokes, " On the theories of internal friction of fluids in motion", Trans Cambr. Phil. Soc. 8, 1845, 287-305.

[5] T. von Ka`rma`n, “ Ueber laminare und turbulente reibung”, ZAMM, 1, 1921, 233-255.

[6] W. G. Cochran, "The flow due to a rotating disc", Proc. Cambridge Phil. Soci., 30, 1934, 365- 375.

[7] E. R. Benton, "On the flow due to a rotating disk", J. Fluid Mech., 24, Part-4, 1966, 781-800.

[8] L. Howarth, 'The boundary layer in three dimensional flow", Part I, Phil. Mag. 42, 1951, 223.

[9] A. G. Hansen, "Possible similarity solution of the laminar incompressible boundary layer equation", ASME paper 57A, 1957, 79.

[10] Md. Zakerullah, and Kh. A. Maleque, "Laminar Combined Convective Flow about a Vertical Inclined Surface," Journal of Bangladesh Academy of Science, Vol. 20, No. 2,12996, pp.99-110, ISSN 03788121.

[11] Md. Zakerullah, and Kh. A. Maleque, "Similarity Requirements For Combined Forced and Free Convective Laminar Boundary Layer Flow over a Vertical Curvilinear Surfaces," Journal of Bangladesh Academy of Science, Vol. 22, No. 1, 1998, 79-90, , ISSN 0378-8121.

[12] T. Allen and N. Riley, The three dimensional boundary layer on a yawed body of revolution, Journal of Engineering Mathematics, 28, 1994, 345.

[13] T. K. Al-Doss, H. A. Jerrah and B. J. Shirer, Mixed convection for a vertical cylindrical embedded in a porous medium, Int. J. Heat and Mass Transfer, 39(6), 1996, 1140 .

[14] H. K. Kuiken, The effect of normal blowing on the flow near a rotating disk of infinite extent, J. Fluid Mech., 47, 1971, 789-798, C845.

[15] A. L. Hassan,. A, and Hazem Ali Attia,. Flow due to a rotating disk with Hall effect, Physics Letters A 228, 1997, 246-290.

[16] Kh. A. Maleque, and M. A. Sattar, "Transient Convective Flow Due to a Rotating Disc with Magnetic Field and Heat Absorption Effects," Journal of Energy, Heat and Mass Transfer, Madras, India, vol. 25, 2003, pp.279-29. ISSN \$ 0970- 9991.

[17] Kh. A. Maleque, and M. A. Sattar, " MHD Convective flow Due to a Rotating Disk with Hall Effect," Journal of Energy, Heat and Mass Transfer, madras, India, Vol. 27, 2005, pp.211-228, ISSN \$ 09709991.

[18] Kh. A. Maleque, and M. A. Sattar, "The effects of variable properties on steady laminar convective flow due to a porous rotating disc," ASME
Journal of Heat Transfer, Technical Brief, Vol. 127, No.12, December 2005. (ISSN 0022-1481)

[19] Kh. A. Maleque, and M. A. Sattar, "The effects of variable properties and Hall current on steady MHD compressible laminar convective fluid flow due to a porous rotating disc," International Journal of Heat and Mass Transfer, Vol. 48, pp.4963-4972, Nov.2005. ISSN: 0017-9310.

[20] Kh. A. Maleque, "Effects of Combined Temperature- and DepthDependent Viscosity and Hall Current on an Unsteady MHD Laminar Convective Flow Due to a Rotating Disk," Chemical Engineering Communications (Taylor and Francis), vol. 197, pp. 506-521, 2009.ISSN 0098-6445

[21] Kh. A. Maleque,"Magnetohydrodynamic Convective Heat and Mass Transfer Due to a rotating Disk with Thermal Diffusion Effect." ASME Journal of Heat Transfer, USA, Vol. 131, Issue 8, 082001(8 pages), August 2009. (ISSN 0022-1481)

[22] A. Acrivos, M. J. Shah, and E. E. Petersen, On the Flow of a NonNewtonian Liquid on a Rotating Disk, J. Applied Physics, 31, 6, 963968 (1960).

[23] Mitschka, P. and Ulbreache, J., Nicht-Newtonsche Flussigkeiten, IV. Stromung Nicht-Newtonscher Flussigkeiten Ostwald-de Waeleschn Typs in der Umgebung Rotierender Drekhegel und Schieben, Coll. Czech. Chem. Comm., 30, 2511-2526 (1965).

[24] T. A. Rogovskii and Z. R. Gorbis, Rheodynamics of a disk rotating in a non-Newtonian liquid, J. Engineering Physics and Thermophysics, 28, 1, January, 54 - 59 (1975).

[25] Sharma, H. G.; Gupta, D. S.Flow of a non-Newtonian second-order fluid under an enclosed rotating disc with uniform suction and injection, J. Aeronautical Society of India, 33, 81-87 (1981).

[26] A. A. Rashaida, D. J. Bergstrom , R. J. Sumner, Mass Transfer From a Rotating Disk to a Bingham Fluid, ASME J. Applied Mechanics, 73, 1, 108-111 (2006).

[27] Cassson N,In: Mill CC, editor. Rheology of disperse systems, vol.84.Oxford: Pergamon press; 1959.

[28] Eldabe NTM, Salwa MGE. Heat transfer of MHD non-Newtonian Casson fluid flow between two rotating cylinder. J Phys Soc Jpn 1995;64:41-64.

[29] Dash RK.Metha KN, Jayaraman G. Casson fluid flow in a pipe filled with a homogenous porous medium. Int J Eng Sci 1996;34(10):114556.

[30] Mustafa M, Hayat T, Pop I, Aziz A. Unsteady boundary layer flow of a Casson fluid due to an impulsively started moving flat plate. Heat Transfer-Asian Res 2011; 40(6):563-76.

[31] Nadeem S, Ul Haq R,Lee C. MHD flow of a Casson fluid over an exponentially shrinking sheet. Sci Iran 2012;19(6):1550-1553.

[32] Swati Mukhopadhyay, Prativa Ranjan De, Krishnendu Bhattacharyya, G.C. Layek, Casson fluid flow over an unsteady stretching surface, Ain Shams Engineering Journal (Engineering Physics and Mathematics), 2013, 4, 933-938.

[33] S. Nadeem , Rizwan UI Haq, Noreen Sher Akbar, Z. H. Khan , MHD three-dimensional Casson fluid flow past a porous linearly stretching sheet." Alexandria Engineering Journal, 2013, 52, 577-582.

[34] Kh. A. Maleque., and Ghose, Prodip K., “ Non-Newtonian Casson Fluid Heat and Mass Transfer Flow and Viscous Dissipation with a Binary Chemical Reaction", The AIUB Journal of Science and Engineering (AJSE), Vol-14, No. 1, pp 201-214, August 2015, ISSN 1608-3679.

[35] Kh. A. Maleque, MHD Non-Newtonian Casson Fluid Heat and Mass Transfer Flow with Exothermic/Endothermic Binary Chemical Reaction and Activation Energy," American Journal of Heat and Mass Transfer , Vol. 3 No. 1 pp. 166-185, (2016).

[36] Kh. A. Maleque (2016) Unsteady MHD Non-Newtonian Casson Fluid Flow due to a Porous Rotating Disk with Uniform Electric Field." Fluid Mech Open Acc 3: 123. doi:10.4172/fmoa1000123.

[37] Kh. A. Maleque, and M. A.Sattar, " Locally Similar Solution of an Unsteady MHD Flow Due to a Rotating Disc with Hall Effect," Journal of Energy, Heat and Mass Transfer, madras, India, Vol. 27, pp.293-303, 2005. ISSN \$ 0970- 9991

[38] Blums, E., Mikhailov, Yu. A., and Ozols, R., 1987. Heat and Mass Transfer in MHD flows, World Scientific Publishing Co. Pte. Ltd, pp. 124.

[39] Kh. A. Maleque, "Effects of Binary Chemical Reaction and Activation Energy On MHD Boundary Layer Heat and Mass Transfer Flow with Viscous Dissipation and Heat Generation/ Absorption," ISRN 
Thermodynamics, vol. 2013, Article ID 284637, 9 pages, 2013.:10.1155/2013/284637. ISSN: 2090-5211

[40] Kh. A. Maleque, "Effects of Exothermic/Endothermic Chemical Reactions with Arrhenius Activation Energy on MHD Free Convection and Mass Transfer Flow in Presence of Thermal Radiation," Journal of Thermodynamics, Volume 2013, Article ID 692516, 11 pages, 2013. . ISSN: 2090-5211

[41] Nachtsheim, P. R., and Swigert, P., 1965. Satisfaction of asymptotic boundary conditions in numerical solution of system of nonlinear of boundary layer type, NASA TN-D3004.

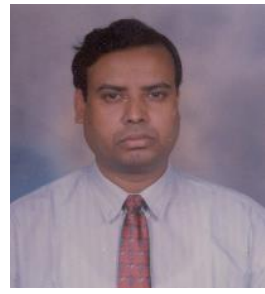

Dr. Kh. Abdul Maleque was born in Tangail, Bangladesh, in 1966. He received the M. Sc. degree in Applied Mathematics from Dhaka University, Bangladesh, the M. Phil. degree in Applied Mathematics from Bangladesh University of Engineering and Technology (BUET) and the $\mathrm{Ph}$. D. degree in Applied Mathematics from Dhaka University, Bangladesh. He joined as a Faculty member in the Department of Mathematics, American International UniversityBangladesh, Dhaka, Bangladesh (AIUB) in 1996. At present, he is serving as a professor at AIUB. His field of research interest is Fluid Mechanics (Incompressible/Compressible flow, Flow due to rotating disk, MHD flow, Polar fluid flow, Convective flow etc). He has 30 foreign publications and 15 local publications in the various fields of Fluid Mechanics. He is a reviewer of the following renowned Journals: International Journal of Heat and Mass Transfer; Chemical Engineering Communications USA; Latin American Applied Research (An International Journal, Heat and Mass Transfer division) Argentina; The AIUB Journal of Science and Engineering, Bangladesh; Bangladesh Journal of Scientific and Industrial Research, Bangladesh; The Journal of Lithuanian Association of Nonlinear Analysts (LANA); Indian Journal of Mathematics (IJM)/Bulletin of the Allahabad Mathematical Society (BAMS). 